\title{
Subjective impairment and social recovery after closed head injury
}

\author{
M I CHA EL O D D , M I CHA E L H M P H R Y, A N D \\ D A V I D U T T L E Y \\ From the Department of Psychology, St George's Hospital Medical School, and Department of \\ Neurosurgery, Atkinson Morley's Hospital, London
}

S U M MARY The level of social recovery achieved by a representative series of 50 young adults was assessed six months after a severe closed head injury (post-traumatic amnesia $>24$ hours). Work, leisure activities, and contact with friends were the areas of life most affected, whereas family life and marital relationships appeared to withstand changes at this stage in the recovery process. Many patients were still suffering from subjective symptoms, but these appeared to have relatively minor effects on ability to resume normal activities. Physical disability was a much more important factor at this stage. A control group of patients with limb injuries suffered similar disruption of their lives, but reported few subjective complaints.

Previous studies of recovery and rehabilitation after closed head injury have been unsatisfactory in several respects. First, there have been ambiguities in selection criteria and in the description of study populations. Despite the wealth of evidence showing that duration of unconsciousness and post-traumatic amnesia (PTA) are good prognostic indices, other criteria have often been preferred. Thus patients have been selected on either multiple factors (Hpay, 1971) or idiosyncratic factors, such as length of time in hospital (London, 1967). Many studies have selected patients by criteria which ultimately depend upon local service arrangements, since only patients treated in a particular specialist unit are included (Gerstenbrand, 1969; Wilkinson, 1969; Richardson, 1971; Bruckner and Randle, 1972; Gjone et al., 1972).

Secondly, age distribution has varied widely from one sample to another. Except in studies of head-injured children there has usually been no restriction on age range. This lack of comparability between samples is all the more regrettable in view of the well-established finding that recovery from head injury is inversely proportional to age (Field, 1976).

Thirdly, follow-up assessments have been performed at widely varying intervals, ranging in

Address for reprint requests: Dr M. Humphrey, Reader in Psychology, St George's Hospital Medical School, Tooting, London SW17.

Accepted 14 February 1978 different studies from one month to 40 years (Field, 1976). Even within the same study the interval has tended to be inconsistent, making comparison still more hazardous.

Finally, there has been no uniformity in the measures of outcome used, and until recently little sign of concern with this problem. Specialised studies have used measures of cognitive recovery (Mandleberg and Brooks, 1975) or psychiatric morbidity (Fahy et al., 1967). The more general studies have usually included information on neurological deficits at follow-up as well as some index of social recovery, such as return to work. Evidence of this kind would be more useful if it had been presented in clearly defined rather than vague and overlapping categories.

Outcome may be measured in terms of either persistence of symptoms or resumption of normal activities. This distinction is important in that some patients may function poorly though almost symptom-free, while others function normally in spite of persisting symptoms. Recovery of social activities will depend partly on the actual symptoms experienced, although it may be hard to predict which symptoms will prove most troublesome in the individual case.

Return to work has been the dominant theme in studies of social recovery after head injury. Other aspects of life, which may be equally important to the patient, have been relatively neglected in the literature. The ability to resume 
normal work is nevertheless a crucial factor, especially in the youthful group most commonly involved. The findings from most studies on resumption of work have given grounds for optimism, with figures typically in the $80-90 \%$ range except where there is a history of prolonged coma (Rowbotham et al., 1954; Carlsson et al., 1968; Steadman and Graham, 1970). Even among patients who have been unconscious for more than a month the chances of return to work may be at least $50 \%$ (Lewin, 1968; Lecuire et al., 1971).

In contrast only two studies have focused on resumption of leisure and social activities. Hpay (1971) found that $65 \%$ of her sample were able to return to their previous social life, while $14 \%$ became "complete social outcasts." However, no details were given. Bond (1975) and Bond and Brooks (1976) devised a scale to embrace various aspects of social recovery including work, family life, and leisure activities. The latter were found to be among the most severely disrupted areas of life.

The aim of the present study was to seek evidence as to the resumption of a wider range of activities than previous investigators have considered. Efforts were made to avoid limitations arising from the use of narrow or imprecise criteria in the selection of patients.

\section{Patients and methods}

A consecutive series was collected of 54 patients aged 16-39 years with closed head injury leading to a PTA of more than 24 hours. This was defined as the time before the return of continuous dayto-day memory after the accident, and was assessed in each case by one of us (MO) during the acute phase after injury. The patients were admitted to seven hospitals in Surrey, Sussex, and South-West London under the care of neurologists or orthopaedic, general, or neurological surgeons.

A control group of 35 patients who had suffered traumatic limb fractures but without injury to the head were also seen. The two groups were matched for age and socioeconomic status.

Of the 50 head injury patients followed up, 24 had a PTA of between one and seven days, and 26 had a PTA of more than seven days. Fortyfive were involved in road traffic accidents, two in riding accidents, and three in industrial accidents. Fifty per cent were aged 16-20 years and $80 \%$ were under 25 years of age.

Clinical features associated with the head injury are shown in Table 1. Eight patients required neurosurgery.
Table 1 Clinical features associated with head injury

\begin{tabular}{lc}
\hline Clinical features & Number of cases \\
\hline All skull fractures & 19 \\
Depressed skull fractures & 7 \\
Subdural haematoma & 5 \\
CSF/blood at the orifices & 9 \\
Early epilepsy & 9 \\
Non-neurological injuries & 32 \\
\hline
\end{tabular}

A close relative, normally a parent or spouse, was used as the source of information. The relative was contacted during the first four weeks after the accident, the exact time depending on the state of the patient. At this stage the relative was interviewed by one of us (MO) in order to make an assessment of the patient's pretraumatic behaviour and social adjustment. A semistructured interview, adapted considerably from that of Weissman and Paykel (1974), was used to assess social adjustment during the two months before the accident. The Katz Adjustment Scale (Katz and Lyerly, 1963), a task distribution check list, and the Wakefield Depression Inventory (Snaith et al., 1971) were also administered. The patient and relative were seen again both six months and 12 months after the injury. The same assessment was repeated on each follow-up visit with the relative, and the patient was given cognitive tests and assessed on a scale for activities of daily living. A symptom check list (available fromo the first author on request) was constructed and administered to both patient and relative on each occasion. This contained 37 items relating to personality changes and somatic, sensory, cognitive, and psychiatric symptoms.

The present report is confined to the six month follow-up when 49 patients were seen. A relative was also seen in all but one case, and in an additional case the relative was seen in the patient's absence. Two patients could not be contacted, one had gone abroad, and two declined to be interviewed. Only the interview material and symptom check list will be included in this preliminary analysis.

\section{Results}

\section{SOCIAL RECOVERY}

This was assessed in the following terms: return to work, contact with friends, leisure activities, family life, marital relationship, parental behaviour, and financial situation.

The results were assessed by comparing previous role performance (as reported by the relative within a month of the accident) and role performance in the two months before the follow-up assessment at six months. 
For certain comparisons the head-injured group is divided according to whether PTA was between one and seven days ("severe" head injuries according to the classification used by Russell, 1971) or longer than seven days ("very severe"). Where relevant, comparisons will also be made with the control group of patients recovering from traumatic limb fractures.

\section{Work}

Fourteen patients were in the professional/ managerial classes of the Registrar General's scale, including a doctor, a graduate engineer, a teacher, and a social worker. A further 17 patients were skilled non-manual workers, and only five were in the lowest (unskilled) category.

Of the 45 patients who had been working fulltime before their injury, only 22 had returned to work full-time for the period four to six months after iniury. Sixteen had not worked at all since their injury, and seven had worked either parttime for all of this period or full-time for part of it. Of those who returned to work all were able to resume at the same level if not in the same job.

The less severely injured group enjoyed a clear advantage in speed of return to work (Table 2). The correlation between PTA and length of delay was $0.41(P<0.003)$. Other indices of the severity of the head injury in the acute phase (Table 1) failed to show any effects on the time taken to return to work although, with the exception of skull fractures, numbers were very small. There was a trend, not quite reaching statistical significance, for those who had returned to work to be judged by their relatives to be less satisfied with their work than before their accident. In the more severely injured group five out of the seven who had returned to work were reported to be less interested in their work, three markedly so. However, among the control group there was a tendency for relatives to report patients to have less job satisfaction on their return after lengthy periods of sick leave $(\mathrm{P}<0.04$, sign test).

This finding may be interpreted as reflecting the difficulties inherent in returning to work after some weeks or months of absence, rather than any particular difficulties experienced by the headinjured patients due to impaired cortical function.

Table 2 Return to work within six months of injury

\begin{tabular}{lccc}
\hline Patient category & Part-time & Full-time & Not working \\
\hline PTA 1-7 days & 2 & 15 & 4 \\
PTA > 7 days & 5 & 7 & 12 \\
Controls & 10 & 19 & 1
\end{tabular}

$\overline{\text { Figures refer to patients who had been working full-time before injury. }}$
Moreover, some of the latter were handicapped by associated limb injuries, one was paraplegic, three were hemiplegic, one had lost an arm, and one was partially blind.

\section{Leisure activities}

There was a marked deficit in the ratings of leisure activities in the very severe group $(P<0.01$, sign test), but this failed to reach significance in the less severely injured. Even in the very severe group, however, more than half were rated as having suffered no such deficit. The control group also suffered a significant reduction of leisure activities $(P<0.01)$, which suggests that interruption of normal life rather than brain injury may be the critical factor. Although $46 \%$ of the patients were not fully back at work and $38 \%$ had impaired leisure activities, these two groups were fairly distinct (Table 3). In all, 34 patients $(68 \%)$ had suffered some impairment in at least one of these areas of their lives.

Table 3 Severity of head injury in relation to impairment of work and leisure

\begin{tabular}{|c|c|c|c|c|}
\hline & \multicolumn{4}{|l|}{$P T A$} \\
\hline & \multicolumn{2}{|l|}{$1-7$ days } & \multicolumn{2}{|l|}{$>7$ days } \\
\hline & \multicolumn{4}{|c|}{ Impairment of work } \\
\hline & Present & Absent & Present & Absent \\
\hline \multicolumn{5}{|c|}{$\begin{array}{l}\text { Impairment of } \\
\text { leisure activities }\end{array}$} \\
\hline $\begin{array}{l}\text { Present } \\
\text { Absent }\end{array}$ & $\begin{array}{l}1 \\
5\end{array}$ & $\begin{array}{r}7 \\
11\end{array}$ & $\begin{array}{r}7 \\
10\end{array}$ & $\begin{array}{l}4 \\
5\end{array}$ \\
\hline
\end{tabular}

Table 4 reveals that these 34 patients had suffered a disproportionately high rate of physical disability. In most cases this consisted of limb fractures and miscellaneous injuries unrelated to brain damage; however, the five cases of mild to severe hemiplegia were included in this analysis. Physical disability was present in all eight patients with impairment of both work and leisure activities.

Table 4 Physical disability and impairment of work and leisure activities in head injury group

\begin{tabular}{lcc}
\hline & \multicolumn{2}{l}{ Impairment of work and leisure activities } \\
\cline { 2 - 3 } & Present & Absent \\
\hline $\begin{array}{l}\text { Hemiplegia or other } \\
\text { physical injuries }\end{array}$ & 29 & 4 \\
$\begin{array}{l}\text { Present } \\
\text { Absent }\end{array}$ & 5 & 12 \\
& $x^{2}=15.04, \mathrm{P}<0.001$ \\
\hline
\end{tabular}


The relationship between physical incapacity and impaired work and leisure cannot be attributed entirely to a greater severity of the head injury itself, since associated disability was present in 17 out of 26 patients with very severe head injury and 13 out of 24 patients with less severe head injury $\left(\chi^{2}=0.27, \mathrm{~ns}\right)$.

\section{Boredom}

Patients in the head-injured group were significantly more often bored than they had been before their injuries $(P<0.005)$. In the very severe group this tendency was more marked than in the less severe patients, where it did not reach significance. No such tendency was reported for the control group, despite lengthy periods off work and a similar interference with leisure activities. Remarkably there was no apparent relationship between boredom and resumption of work or leisure activities.

\section{Social contact}

Several ratings were made under this heading: number of close friends, number of acquaintances, frequency of making and receiving visits, frequency of social outings, social discomfort, and loneliness. A composite measure of social contact was derived by summating unweighted scores on each item.

There was no evidence of any diminution in the number of friends or acquaintances for either the control group or the head injury group as a whole. However, for the very severely injured among the latter there was a significant fall in the number of close friends reported by relatives at the six month follow-up $(P<0.04)$. Again only in the very severe group was there evidence of a lower exchange of visits with friends as compared with before the accident, which in some cases had led to social isolation.

In neither the head-injured nor the control group was there evidence of significantly less social contact among those who were still unemployed (Mann-Whitney test).

\section{Family relationships}

Because of the very different nature of the relationships involved, different sets of ratings were made for single and married patients with respect to their parental families.

There was no change in either the frequency of contact or level of friction between married patients and their parents or in-laws. There were no significant changes in the amount of friction between single patients and their parents or siblings. However, there was a non-significant tend- ency towards more friction in both head-injured and control families.

In the very severely injured group single patients were apt to become more dependent on parents (sign test, $\mathrm{P}<0.02$ ), but this did not reach significance among the control group or the less severe head injuries. No such significant trend was found for married patients in relation to either parents or spouses.

\section{Marital relationships}

Only 12 head-injured and six control patients were married. With such small numbers it was not possible to demonstrate significant changes. In only one of the 12 head-injured cases was the relationship reported to be appreciably worse. No spouses reported any sexual problems persisting into the fifth and six months, and an increase in frequency of intercourse was reported as often as a decrease.

\section{SUBJECTIVE SYMPTOMS}

The symptom check list elicited more than one complaint from the majority of patients. Six months after injury only $23 \%$ claimed to be symptom-free, while $35 \%$ mentioned six or more symptoms (Table 5). The number of symptoms showed a weak but positive association with PTA $(r=0.30, \mathrm{P}<0.02)$ and time before return to work $(r=0.27, \mathrm{P}<0.04)$. There was no relationship between number of symptoms and sex, social class, or pursuit of a compensation claim.

\section{Table 5 Subjective symptoms at six months}

\begin{tabular}{lll}
\hline Number of symptoms & $\begin{array}{l}\text { Number of patients } \\
\text { working full-time }\end{array}$ & $\begin{array}{l}\text { Number of patients } \\
\text { not working full-time }\end{array}$ \\
\hline 0 & 8 & 3 \\
1 & 1 & 0 \\
$2-5$ & 8 & 10 \\
$6-10$ & 3 & 4 \\
$11-21$ & 2 & 6 \\
\hline
\end{tabular}

The symptoms most frequently reported are shown in Table 6. Thirty-one patients $(65 \%)$ still suffered from at least one of the most frequent triad of symptoms: poor memory, loss of temper, and fatigue. Cognitive and personality changes appeared to predominate.

The patients in the very severe group were more prone to complain of subjective symptoms than those in the less severe group (mean number $=6.4$ and 4.1 respectively, $t=2.12, \mathrm{P}<0.05$ ). Despite these quantitative differences, the general impression given is that the two subgroups complained of rather similar symptoms. Patients and relatives gave a similar account of the symptoms 
Table 6 Symptoms most frequently reported by patients and relatives

\begin{tabular}{|c|c|c|c|}
\hline \multicolumn{2}{|l|}{ Patients $(n=48)$} & \multicolumn{2}{|l|}{ Relatives $(n=48)$} \\
\hline $\begin{array}{l}\text { Trouble remembering } \\
\text { things } \\
\text { Often loses temper } \\
\text { Becomes tired very easily } \\
\text { Has difficulty } \\
\text { concentrating when } \\
\text { reading } \\
\text { Often irritable } \\
\text { Often impatient } \\
\text { Often restless } \\
\text { Finds difficulty in } \\
\text { becoming interested } \\
\text { in anything }\end{array}$ & $\begin{array}{l}(14) \\
(14) \\
(13) \\
(13)\end{array}$ & $\begin{array}{l}\text { Trouble remembering } \\
\text { things } \\
\text { Becomes tired very easily } \\
\text { Often impatient } \\
\text { Often loses temper } \\
\text { Often irritable } \\
\text { Has difficulty with eyes } \\
\text { Sometimes bumps } \\
\text { into things } \\
\text { Often restless }\end{array}$ & $\begin{array}{l}(21) \\
(18) \\
(17) \\
(19) \\
(15) \\
(12) \\
\\
(11) \\
(10)\end{array}$ \\
\hline
\end{tabular}

experienced, order of frequency being highly correlated (Spearman's rho $=0.87$ ). But there were marked discrepancies in individual cases, which underlines the hazards of accepting the patient's report as definitive.

Control patients reported fewer symptoms and with a different emphasis. Fifty-eight per cent were symptom-free and only $20 \%$ complained of more than three symptoms. No particular symptoms were mentioned frequently, but those reflecting anxiety and depression were amongst the more frequent. Intergroup comparison thus suggests that there are indeed subjective complaints that commonly occur after head injury (cf. the "post-concussional syndrome") but occur less frequently after injuries to other parts of the body.

\section{Discussion}

In general, our findings may be regarded as encouraging. Despite having suffered severe head injuries only six months earlier, most of our patients had resumed many if not all of their social activities. Only among the very severely injured (PTA>seven days) was marked disruption still apparent. Furthermore, some of the adverse effects were as commonly encountered after accidental injury to other parts of the body. At the same time a third of the head-injured patients had failed to return to work during the first six months, and a similar proportion had been unable to resume their leisure activities. The fact that these two groups were not the same emphasises the importance of looking at social recovery in a wider context than work alone.

The relationship between work and social contact is of particular interest. Social isolation was confined to patients with very severe head injuries, who were also least likely to be back at work. The control group had not become isolated either through absence from work or physical disability. It therefore appears more likely that the social problems of the head injury group were a reflection of personality changes such as restlessness, irritability, and impatience. It is these which, especially when combined with physical or sensory impairment, pose a major challenge to rehabilitation.

There was no evidence that at this stage in the recovery process the patient's family or marital relationships were prone to greatly increased friction, despite the fact that many patients were reported as showing personality changes. It is possible that the family may "rally round" initially but may not be able to sustain this indefinitely. Patients are currently being followed up at later stages in their recovery to investigate this possibility.

The greater dependence of single patients was confined to the very severe head injury group, whose physical disabilities were comparable to those of the control group. Also, although both the very severe head injury patients and the controls had reduced involvement in leisure activities, only the former were found to be significantly more bored. These two findings give a tentative indication that the head injury had effects which went further than physical impairment and the psychological impact of an accident. In the main, however, our findings would suggest that at this stage in the recovery process, the consequences of other major injuries can have a more retarding effect on social recovery than the head injury itself.

It is perhaps surprising that patients suffering from many subjective symptoms were often able to return to work or resume their social activities. It appears that these young people had refused to allow potentially incapacitating symptoms to militate against their return to normal living. Even where a claim for damages was in progress (as in 20 cases) there was no evidence of any adverse effect on social recovery; more specifically, there was no statistical association between delay in return to work and litigation. Among young adults the motivation to lead a normal life appears to outweigh that of purely financial gain.

This study was financed by the National Fund for Research into Crippling Diseases. We are grateful to the Fund's former Director, Dr Duncan Guthrie, OBE, for his personal support and encouragement. We also thank the consultants who allowed access to their patients.

\section{References}

Bond, M. R. (1975). Assessment of the psychosocial outcome after severe head injury. In Outcome of 
Severe Damage to the CNS. Symposium 34, pp. 141153. Ciba Foundation: London.

Bond, M. R., and Brooks, D. N. (1976). Understanding the process of recovery as a basis for the investigation of rehabilitation for the brain-injured. Scandinavian Journal of Rehabilitation Medicine, 8, 127-133.

Bruckner, F. E., and Randle, A. P. H. (1972). Return to work after severe head injuries. Rheumatology and Physical Medicine, 11, 344-348.

Carlsson, C. A., Von Essen, C., and Lofgren, J. (1968). Factors affecting the clinical course of patients with severe head injuries. Part 1 . Influence of biological factors. Part 2. Significance of posttraumatic coma. Journal of Neurosurgery, 29, 242251.

Fahy, T. J., Irving, M. H., and Millac, P. (1967). Severe head injuries-a six year follow-up. Lancet, 2, 475-479.

Field, J. H. (1976). Epidemiology of Head Injuries in England and Wales. Her Majesty's Stationery Office: London.

Gerstenbrand, F. (1969). Rehabilitation of the headinjured. In Late Effects of Head Injury. Edited by A. E. Walker et al. Charles C. Thomas: Springfield, Illinois.

Gjone, R., Kristiansen, K., and Sponheim, N. (1972). Rehabilitation in severe head injuries. Scandinavian Journal of Rehabilitation Medicine, 4, 2-4.

Hpay, H. (1971). Psycho-social effects of severe head injury. In Proceedings of an International Symposium on Head Injuries. Churchill Livingstone: Edinburgh.

Katz, M. M., and Lyerly, S. B. (1963). Methods of measuring adjustment and social behavior in the community. I. Rationale, description, discriminative validity and scale development. Psychological Reports, 13, 503-535.
Lecuire, J., Dechaume, J. P., and Deruty, R. (1971). Long-term prognosis of the prolonged and serious traumatic comas. In Proceedings of an International Symposium on Head Injuries. Churchill Livingstone: Edinburgh.

Lewin, W. (1968). Rehabilitation after head injury. British Medical Journal, 1, 465-470.

London, P. S. (1967). Some observations on the course of events after severe injury of the head. Annals of the Royal College of Surgeons of England, 41, 460-479.

Mandleberg, I. A., and Brooks, D. N. (1975). Cognitive recovery after severe head injury. 1. Serial testing on the Wechsler Adult Intelligence Scale. Journal of Neurology, Neurosurgery, and Psychiatry, 38, 1121-1126.

Richardson, J. C. (1971). The late management of industrial head injuries. In Proceedings of an International Symposium on Head Injuries. Churchill Livingstone: Edinburgh.

Rowbotham, G. F., MacIver, I. N., Dickson, J., and Bousfield, M. E. (1954). Analysis of 1400 cases of acute injury to the head. British Medical Journal, 1, 726-730.

Russell, W. R. (1971). The Traumatic Amnesias, p. 32, Oxford University Press: Oxford.

Snaith, R. P., Ahmed, S. N., Mehta, S., and Hamilton, M. (1971). Assessment of the severity of primary depressive illness. Psychological Medicine, 1, 143149.

Steadman, J. H., and Graham, J. G. (1970). Head injuries: an analysis and follow-up study. Proceedings of the Royal Society of Medicine, 63, 23-28.

Weissman, M. M., and Paykel, E. S. (1974). The Depressed Woman-a Study of Social Relationships. University of Chicago Press: Chicago.

Wilkinson, M. I. P. (1969). The prognosis of severe head injuries in young adults. Proceedings of the Royal Society of Medicine, 62, 541-542. 